\title{
Measurement of aortic pulse wave velocity in CMR: comparison of transit time estimators
}

\author{
Anas Dogui, Alban Redheuil, Muriel Lefort, Alain Decesare, Alain Herment, Elie Mousseaux* \\ From 2011 SCMR/Euro CMR Joint Scientific Sessions \\ Nice, France. 3-6 February 2011
}

\section{Objectives}

To investigate the efficacy of a new method (TT-Upslope) for transit time $(\Delta t)$ estimation from phase contrast CMR flow curves, and to compare it with three previously described methods based on the commonly used foot-tofoot approaches, as well as the point-to-point and waveto-wave approaches.

\section{Background}

CMR is increasingly used for measuring aortic arch PWV (arch-PWV) by using accurate aortic length and transit time between flow waves. If robust aortic length measurement is an obvious strength of CMR thanks to many $3 \mathrm{D}$ imaging approaches available, $\Delta \mathrm{t}$ measurement remains a major challenge. Consequently, different methods have been previously described to estimate the $\Delta \mathrm{t}$ using CMR, but there is to date no fully standardized method for its determination.

\section{Methods}

Fifty healthy subjects underwent carotid-femoral pulse wave velocity (cf-PWV), and carotid pulse pressure (CPP) measurements by applanation tonometry, as well as CMR exams with steady-state free-precession (SSFP) and Phase Contrast (PC) acquisitions at the level of the aortic arch. These data were used for the automated estimation of the arch-PWV, and the aortic areas of the ascending aorta, which were combined with CPP to estimate the local distensibility (aa-Dist). The 3D length of the aortic arch was calculated from axial and coronal SSFP acquisitions. $\Delta t$ was defined as the time shift between the flow curves of the ascending (CA) and descending (CD) aorta and calculated with: 1) TT-Upslope by minimizing the area delimited by two sigmoid curves fitted to the systolic up-slope of CA and CD, 2) TT-Point using the half maximum of CA and CD, 3) TT-foot using CA and CD feet, 4) TT-Wave by minimizing the area between the whole CA and the CD curves using the cross correlation technique.

\section{Results}

The arch-PWV estimated with both estimators TTUpslope and TT-Wave resulted in a better correlation with aging, cf-PWV, as well as aa-Dist (Table 1). Furthermore, the TT-Upslope method resulted in a higher reproducibility (4\%), a better correlation of archPWV with aa-Dist according to the Bramwell-Hill equation, and less overlap between the $\leq 37$ years $(n=25)$ and $\geq 38$ years $(\mathrm{n}=25)$ age groups.

\section{Conclusions}

TT-Upslope and TT-Wave appear to be less sensitive to the low temporal resolution, signal-to-noise ratio, and varying profile of velocity curves. Indeed, they avoid the restriction of the analysis to a few points of the velocity curve, and provide better correlations with the physiological and stiffness parameters.

\begin{tabular}{|c|c|c|c|}
\hline & Linear regression & Power regression & \\
\hline$\Delta \mathrm{t}$ estimators & Age/arch-PWV & cf-PW/arch-PWV & arch-PWV/aa-Dist \\
\hline TT-Wave & $r=0.83 p<0.001$ & $r=0.7 p<0.001$ & $r=0.71 p<0.001$ \\
\hline TT-Upslope & $r=0.83 p<0.001$ & $r=0.69 p<0.001$ & $r=0.81 p<0.001$ \\
\hline TT-Foot & $r=0.47 p<0.001$ & $r=0.34 p<0.013$ & $r=0.61 p<0.001$ \\
\hline TT-Point & $r=0.72 p<0.001$ & $r=0.59 p<0.001$ & $r=0.6 p<0.001$ \\
\hline
\end{tabular}


Cite this article as: Dogui et al:: Measurement of aortic pulse wave velocity in CMR: comparison of transit time estimators. Journal of Cardiovascular Magnetic Resonance 2011 13(Suppl 1):P13.

Submit your next manuscript to BioMed Central and take full advantage of:

- Convenient online submission

- Thorough peer review

- No space constraints or color figure charges

- Immediate publication on acceptance

- Inclusion in PubMed, CAS, Scopus and Google Scholar

- Research which is freely available for redistribution

Submit your manuscript at www.biomedcentral.com/submit
C Biomed Central 